EPV154/\#117 HIV TESTING IN CERVICAL DYSPLASIA, PRACTITIONERS' OPINION

${ }^{1} \mathrm{R}$ van de Laar*, ${ }^{2} \mathrm{C}$ Jordans, ${ }^{3} \mathrm{C}$ Rokx, ${ }^{4} \mathrm{H}$ van Beekhuizen, ${ }^{5} \mathrm{HC}$ van Doorn. ${ }^{1}$ Erasmus MC Cancer Institute, Gynaecological Oncology, Rotterdam, Netherlands; ${ }^{2}$ Erasmus MC, Microbiology and Infectious Diseases, Rotterdam, Netherlands; ${ }^{3}$ Erasmus MC, Internal Medicine, Section Infectious Diseases, Rotterdam, Netherlands; ${ }^{4}$ Erasmus MC Cancer institute, University Medical Center Rotterdam, Gynecologic Oncology, Rotterdam, Netherlands; ' Erasmus MC Cancer Institute, Gynecologic Oncology, Rotterdam, Netherlands

\subsection{6/ijgc-2021-IGCS.224}

Objectives Cervical dysplasia is an HIV indicator condition and according international recommendations HIV testing is strongly advised in women with cervical dysplasia, because the risk of an undiagnosed HIV is thought to be $>0.1 \%$. Therefore an HIV test should be offered to all women with cervical dysplasia. There is no literature about the opinion of Gynaecologist on HIV screening in patients with cervical dysplasia.

Methods We sent an online questionnaire to gynecologist in South West Netherlands to investigate 1) what they know about this issue, 2) their opinion and willingness on active HIV testing for this cervical dysplasia.

Results The questionaire was sent to 103 gynaecologists of whom fifty-six participants replied (54\%). Forty-eight (86\%) think patients are not offended when HIV testing is offered and $50(89 \%)$ have no difficulty to address HIV testing. Thirty-nine $(70 \%)$ gynaecologist think that the prevalence of undiagnosed HIV infection is lower than $0.1 \%$, and only

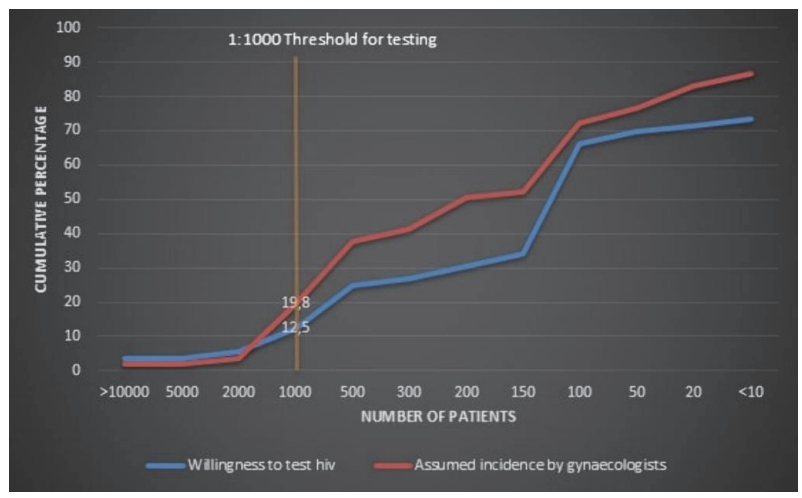

Abstract EPV154/\#117 Figure 1

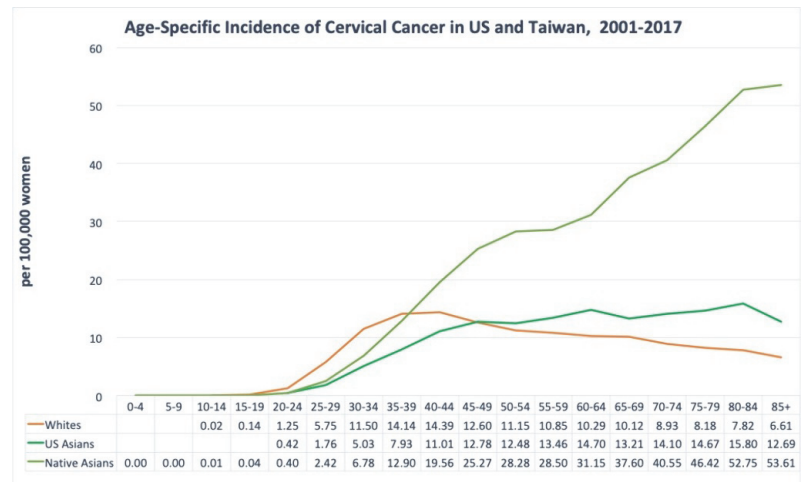

-Whites -US Asians —Native Asians

Abstract EPV155/\#210 Figure 1 Age-specific incidence of cervical cancer in US and Taiwan, 2001-2017 seven $(12,5 \%)$ accept HIV testing in case of a prevalence of $0.1 \%$ or less. Thirthy-two $(57 \%)$ are willing to test with a prevalence of $1 \%$ or higher.

Conclusions To address and offer HIV testing seems not an issue for the gynaecologists questioned in our study. However, the willingness to routinely perform an HIV test for cervical dysplasia at the assumed $0.1 \%$ prevalence looks insufficient and differs from the recommendations of international policy makers. Discussion is needed tot change the treshold or the willingness for testing.

\section{EPV155/\#210 DISPARITIES IN CERVICAL CANCER INCIDENCE IN NATIVE ASIANS VS. US ASIANS - A POPULATION ANALYSIS}

${ }^{1} \mathrm{~A}$ Moon*, ${ }^{2} \mathrm{C}-\mathrm{IL}$ Liao, ${ }^{3} \mathrm{E}$ Thayer, ${ }^{4} \mathrm{~J}$ Chan. ${ }^{1}$ Stanford University School of Medicine, Obstetrics and Gynecology, Division of Gynecologic Oncology, Stanford, USA; ${ }^{2}$ Kaohsiung Veterans General Hospital, Obstetrics and Gynecology, Kaohsiung City, Taiwan; ${ }^{3}$ University of Massachusetts Medical School, Obstetrics and Gynecology, Worcester, USA; ${ }^{4}$ California Pacific Medical Center, Obstetrics and Gynecology, San Francisco, USA

\subsection{6/ijgc-2021-IGCS.225}

Objectives To evaluate the incidence and trends of cervical cancer in native Asians compared to Asians in the United States.

Methods Data were obtained from Taiwan Cancer Registry in Health and Welfare Data Center and United States Cancer Statistics between 2001 and 2017. SEER*Stat 8.3.8, Joinpoint regression program 4.8.0.1, Microsoft Excel calculated the age-adjusted incidence (AAI, per 100,000 women), age-specific incidence (ASI, per 100,000 women), and trends (average annual percent change, AAPC).

Results Compared to US Asians, native Asians had a significantly higher cervical cancer incidence at 7.8 vs. 5.1 per 100,000. Over time, the incidence in Taiwan is improving at a rate of $6 \%$ per year but remains high. Based on age groups, the incidence increased at a younger age in Whites (25-29 years) compared to an older age in US Asians (30-34 years) and native Asians (35-39 years). Although new cases peaked in Whites and US Asians after age 40 and then plateaued in the older age groups, native Asians continued to have an increase into age 80 . In fact, the incidence of cancer in native Asians age 85 and older was 53.6 vs. 12.7 in US Asians, a four-fold difference.

Conclusions After age 40, cervical cancer incidence was increasing every 5 -age years in native Asians while plateauing in the US. Native Asians aged $85+$ years had a four-fold higher incidence of cervical cancer compared to age-matched US Asians. The lack of screening may explain these disparities.

\section{EPV156/\#363 ADEQUACY OF INFORMATION RECEIVED FOR PATIENTS TREATED OVERSEAS AND ITS IMPACT ON CONTINUING TREATMENT AND FOLLOW-UP}

${ }^{1} \mathrm{MT}$ Alsayed*, ${ }^{1} \mathrm{~S}$ Brich, ${ }^{2} \mathrm{H}$ Khaldi, ${ }^{1} \mathrm{~A}$ Magzoub, ${ }^{1} \mathrm{~A}$ Al -Ansari, ${ }^{2} \mathrm{~S}$ Chandramouli, ${ }^{2} \mathrm{JJO}$ Herod. 'Hamad Medical Corporation, Women Wellness and Research Center, DOHA, Qatar; ${ }^{2}$ Hamad Medical Corporation, Women Wellness and Research Center, Doha, Qatar

\subsection{6/ijgc-2021-IGCS.226}

Objectives The gynaecological oncology service in Doha treats all women living in or visiting Qatar. Despite the quality and affordability of the service many women travel overseas for 